\title{
Clinical Presentation of Pulmonary Tuberculosis Associated with Acquired Immunodeficiency Syndrome in Metropolitan Tokyo
}

\author{
Minoru Kanazawa, Akira Fujita*, Takeo Toyoda**, Tomoaki Takasugi**, \\ Mitsuhiko Osumi**, Kazumi Nishio, Akira Suzuki*, Hideo OgatA*** and Kazuo IwaI***
}

The clinical features of pulmonary tuberculosis associated with acquired immunodeficiency syndrome (AIDS) in Japan were surveyed utilizing questionnaires completed by 48 institutes around the Tokyo metropolitan area. We found 11 Japanese and six foreign patients. The average number of patients per institute was 0.37 . The Japanese patients had advanced human immunodeficiency virus (HIV) infection. A middle aged man, with fever and cough, nonspecific chest X-ray infiltrates, decreased lymphocyte counts, and a negative tuberculin skin test was the typical presentation of the Japanese patients. The clinical diagnosis was often difficult. The smear positive rate was high among those from whom smears were obtained, suggesting high communicability. None of the isolates indicated multidrug-resistant tuberculosis at the time of diagnosis. In conclusion, sputum smear and culture remain the keys to diagnosing tuberculosis in patients with AIDS, although the clinical picture may be atypical for pulmonary tuberculosis.

(Internal Medicine 35: 946-952, 1996)

Key words: Japanese AIDS patient, human immunodeficiency virus (HIV), drug-resistant tuberculosis

\section{Introduction}

In 1992, the World Health Organization estimated that four million people, mostly in developing countries, have been infected with both the human immunodeficiency virus (HIV) and Mycobacterium tuberculosis (1). These patients are now diagnosed as having acquired immunodeficiency syndrome (AIDS) (2). Clinical features of pulmonary tuberculosis associated with AIDS have been well documented as being atypical, with non-cavitary disease, lower lung zone predominance of pulmonary infiltrates, hilar and mediastinal lymphadenopathy, pleural effusion, and extrapulmonary involvement (3-11). Recent large series from Africa also indicate that pulmonary tuberculosis patients with HIV-positivity have a higher frequency of small nodular lesions, upper lobe cavitation, lymphadenopathy and diffusely distributed parenchymal infiltrates, as compared with those who are HIV-negative $(12,13)$. The increase in tuberculosis patients with AIDS poses a serious threat and burden to developing countries $(9,14)$. In the United
States and some European countries, a number of institutionbased outbreaks of multidrug-resistant tuberculosis have been reported, with the majority of involved subjects being infected with HIV (15-18). These patients are difficult to treat. The mortality rate is high and death generally occurs within a short time after diagnosis.

This scenario should prompt us to ascertain the current prevalence and clinical features of pulmonary tuberculosis associated with AIDS in Japan. Forty-nine cases of tuberculosis with AIDS have been reported to the relevant members of the Health Science Research Project on AIDS to date (February 1996). The clinical presentation of these patients has not yet been adequately documented. At present, we have a limited number of sporadic case reports of pulmonary tuberculosis with AIDS (19-22). It is true that there will be increasing opportunities to diagnose and treat these patients in our daily practice. We therefore made inquiries regarding this issue at the Respiratory Clinical Conference, which has been held monthly in Tokyo since 1967 (23). We have since collected data on 11

From the Department of Medicine, School of Medicine, Keio University, Tokyo, *the Division of Respiratory Diseases, Tokyo Metropolitan Fuchu Hospital, Tokyo, **the Division of Respiratory Diseases, National Sanatorium Higashi-Saitama Hospital, Hasuda and ***the Fukujuji Hospital, Japan AntiTuberculosis Association, Tokyo

Received for publication May 31, 1996; Accepted for publication September 9, 1996

Reprint requests should be addressed to Dr. Minoru Kanazawa, the Department of Medicine, School of Medicine, Kéio University, 35 Shinanomachi, Shinjukuku, Tokyo 160 
Japanese and six foreign (non-Japanese) patients, all of whom were presented at the Conference held in December 1995. We analyzed the clinical characteristics, chest X-ray and CT findings, drug susceptibility and outcomes of these patients. We report herein the clinical features of pulmonary tuberculosis with AIDS which are considered unique to Japanese patients.

\section{Methods}

\section{Questionnaire}

We asked representatives of 77 institutes, to which participants of the Respiratory Clinical Conference belong, to fill out two questionnaires. Most participants were affiliated with the divisions of pulmonary medicine in either university hospitals or major district hospitals around the Tokyo metropolitan area. In the first questionnaire, we inquired about 1) the total number of beds in the institute, 2) the number of beds in the pulmonary division, 3) the number of beds for tuberculosis patients, 4) the number of outpatients seen daily in the pulmonary clinic, 5) the accumulated number of patients with AIDS hospitalized on the wards of the pulmonary division, 6) the accumulated number of patients with pulmonary tuberculosis associated with AIDS, and 7) the accumulated number of patients with pulmonary atypical mycobacteriosis associated with AIDS. We received replies from 48 institutes (62\%).

The institutes which had patients with pulmonary tuberculosis with AIDS were asked to fill out a second questionnaire for each patient. The major items of inquiry were 1) sex, date of birth, occupation, and nationality of the patient, 2) route and estimated date of HIV infection, 3) outcome, 4) chief complaint and main symptoms, 5) tuberculin skin test, 6) results of smear grade (Gaffky's number; 0 for negative, more than one for positive, 10 as the maximum) and culture, 7) the method used to identify M. tuberculosis, 8) drug susceptibility, 9) chest Xray findings, 10) other laboratory data including CD4 cell counts and CD4/CD8 cell ratio, and 11) complications other than tuberculosis. Among the chest X-ray findings we asked for documentation of 1) vertical distribution of parenchymal infiltrates, 2) presence or absence of cavities, 3) pleural effusion, and 4) hilar and mediastinal lymphadenopathy.

Tokyo Metropolitan Komagome Hospital, which is a leading hospital in the treatment of AIDS in Japan, cooperated in conducting this survey. Based on the information provided in the first questionnaire, the Komagome staff treated 126 patients with AIDS including eight patients with pulmonary tuberculosis. Two patients, who were transferred to Fuchu Hospital, were included in this study. However, individual information on the other six patients (the second questionnaire) was unavailable such that we could not include those patients.

\section{Patients}

All patients were positive for the HIV-1 antibody. The diagnosis of tuberculosis was confirmed by positive culture for M. tuberculosis, in all but one case, by sputum smear findings (Gaffky \#4) and treatment response to antituberculosis drugs. One patient had tracheobronchial tuberculosis, proved by bronchofiberscopic examination, and lymphadenopathy without parenchymal infiltrates in the lung fields (case 1). We included this patient among those with pulmonary tuberculosis because of the involvement of intrapulmonary bronchi and lymph nodes. Two patients had miliary tuberculosis (case 10, case B). All of these patients were presented and discussed with chest X-rays and chest CT scans, at the Respiratory Clinical Conference held on December 22, 1995.

\section{Data analysis}

Data obtained from the questionnaires are summarized in Tables 1-6. Means and ranges of numerical data are presented. Japanese and foreign patients were compared by using the nonparametric Mann-Whitney U-test, and a p value of less than 0.05 was considered significant.

\section{Results}

In the forty-eight responding institutes, we identified 59 patients with AIDS admitted to the wards of puimonary divisions. Among them, we found 17 patients with pulmonary tuberculosis and two with atypical mycobacteriosis. The average accumulated numbers of patients per institute were 1.23 for patients with AIDS admitted to pulmonary wards, and 0.37 for pulmonary tuberculosis associated with AIDS. Tuberculosis was present in $29 \%$ of the pulmonary patients with AIDS. The data obtained from the first questionnaire are summarized in Table 1.

Epidemiological and clinical characteristics of patients with pulmonary tuberculosis associated with AIDS are shown in Table 2. The age distribution of the patients was compared with that of HIV positive patients reported in Japan. Nine of the 11 Japanese patients (83\%) were older than 40 years old (Fig. 1). The most frequent route of HIV infection was heterosexual contact in both groups. Most of these patients were diagnosed as having AIDS in the period from 1992 to 1995 . Tuberculin skin tests were generally negative when done; $100 \%$ for Japanese and $80 \%$ for foreign patients. All had smear positivity, but one patient was only culture positive. Extrapulmonary tuberculosis was present as a complication of AIDS in seven patients (41\%; 5 Japanese, 2 foreign). Three patients had cervical

Table 1. Results of Questionnaire on Pulmonary Tuberculosis Associated with AIDS

\begin{tabular}{lrc}
\hline Numbers of & Total & /Institute \\
\hline Responding institutes & 48 & \\
Total beds & 21,814 & 496 \\
Pulmonary division beds & 1,899 & 43 \\
Beds for tuberculosis & $514(8$ institutes $)$ & 64 \\
Outpatients in pulmonary clinics & $68 /$ day \\
Patients with AIDS admitted to pulmonary wards & 59 & 1.23 \\
Patients with pulmonary tuberculosis with AIDS & 17 & 0.37 \\
Patients with atypical mycobacteriosis with AIDS & 2 & 0.04 \\
\hline
\end{tabular}


Kanazawa et al

Table 2. Epidemiologic and Clinical Characteristics of Patients with Pulmonary Tuberculosis Associated with AIDS

\begin{tabular}{|c|c|c|c|c|c|c|c|c|c|c|c|}
\hline & \multirow{2}{*}{$\begin{array}{l}\text { Age } \\
\text { Sex }\end{array}$} & \multirow{2}{*}{$\begin{array}{c}\text { Route } \\
\text { of HIV } \\
\text { infection\# }\end{array}$} & \multirow{2}{*}{$\begin{array}{l}\text { Date of } \\
\text { diagnosis } \\
\text { for AIDS }\end{array}$} & \multirow{2}{*}{$\begin{array}{c}\text { Tuberculin } \\
\text { skin } \\
\text { test }\end{array}$} & \multirow{2}{*}{$\begin{array}{l}\text { Gaffky's } \\
\text { number* }\end{array}$} & \multicolumn{3}{|c|}{ Peripheral cell counts } & \multirow{2}{*}{ CD4/CD8 } & \multirow[t]{2}{*}{ Outcome } & \multirow[t]{2}{*}{ Institutes } \\
\hline & & & & & & $\begin{array}{c}\mathrm{WBC} \\
\left(/ \mathrm{mm}^{3}\right)\end{array}$ & $\begin{array}{c}\text { Lymphocytes } \\
(\%)\end{array}$ & $\begin{array}{l}\text { CD4 cells } \\
\left(/ \mathrm{mm}^{3}\right)\end{array}$ & & & \\
\hline \multicolumn{12}{|c|}{ Japanese patients; } \\
\hline case 1 & $48 \mathrm{M}$ & hetero & '95.5 & $(-)$ & 7 & 5,400 & 26 & 170 & 0.17 & recovered & HS \\
\hline case 2 & $16 \mathrm{M}$ & blood & unknown & ND & 7 & 4,500 & 58 & 678 & 0.44 & recovered & HS \\
\hline case 3 & $49 \mathrm{M}$ & hetero & '93.7 & $(-)$ & 4 & 7,800 & 16 & 120 & 0.19 & being treated & HS \\
\hline case 4 & $52 \mathrm{M}$ & hetero & $' 94.5$ & ND & 5 & 5,600 & 18 & 5 & 0.04 & being treated & HS \\
\hline case 5 & $70 \mathrm{M}$ & hetero & '94.10 & $(-)$ & 1 & 4,600 & 18 & 25 & 0.17 & deceased & MY \\
\hline case 6 & $49 \mathrm{M}$ & hetero & $' 93.5$ & $(-)$ & 0 & 7,400 & 14 & 25 & 0.07 & deceased & MY \\
\hline case 7 & $52 \mathrm{M}$ & hetero & '92.4 & ND & 8 & 2,700 & 2 & 13 & 0.33 & deceased & KU \\
\hline case 8 & $35 \mathrm{M}$ & homo & '93.2 & ND & 10 & 5,900 & 10 & 5 & 0.02 & deceased & $\mathrm{FH}$ \\
\hline case 9 & $55 \mathrm{M}$ & hetero & '95.6 & $(-)$ & 7 & 6,600 & 2 & 8 & 0.03 & deceased & $\mathrm{FH}$ \\
\hline case 10 & $65 \mathrm{M}$ & homo & '94.6 & ND & 6 & 2,700 & 29 & 6 & 0.10 & deceased & FH \\
\hline case 11 & $48 \mathrm{M}$ & hetero & '94.12 & $(-)$ & 4 & 2,200 & 10 & 7 & 0.06 & deceased & $\mathrm{FH}$ \\
\hline mean & 44 & & & & 5.4 & 5,036 & 18.4 & 97 & 0.14 & & \\
\hline \multicolumn{12}{|c|}{ Foreign patients; } \\
\hline case A & $25 \mathrm{M}$ & hetero & '94.4 & ND & 2 & 4,150 & 33 & 49 & 0.04 & deceased & HS \\
\hline case B & $30 \mathrm{M}$ & hetero & '95.2 & $(-)$ & 1 & 2,800 & 9 & 31 & 0.20 & deceased & FH \\
\hline case $\mathrm{C}$ & $24 \mathrm{~F}$ & hetero & $' 92.10$ & $(-)$ & 8 & 10,400 & 21 & 483 & 0.87 & unknown & FJ \\
\hline case D & $23 \mathrm{M}$ & unknown & $' 92.9$ & $(-)$ & 8 & 4,100 & 18 & 369 & 0.10 & unknown & FJ \\
\hline case $\mathrm{E}$ & $30 \mathrm{M}$ & blood & 93.10 & $(+)$ & 2 & 5,400 & 38 & 438 & 0.35 & being treated & FJ \\
\hline case F & $35 \mathrm{M}$ & homo & '93.10 & $(-)$ & 3 & 6,000 & 9 & 62 & 0.19 & unknown & FH \\
\hline mean & 28 & & & & 4.0 & 5,475 & 21.3 & 239 & 0.29 & & \\
\hline
\end{tabular}

\#hetero: heterosexual contact, blood: blood (product) transfusion, homo: homosexual contact. *Gaffky's number indicates acid-fast smear result, 0 for negative, 1 to 10 for positive, and 10 as the maximum. HIV: human immunodeficiency virus, AIDS: acquired immunodeficiency syndrome, WBC: white blood cell, M: male, F: female, ND: not done, HS: Higashi-Saitama Hospital, MY: Minami-Yokohama Hospital, KU: Keio University Hospital, FH: Fuchu Hospital, FJ: Fukujuji Hospital.

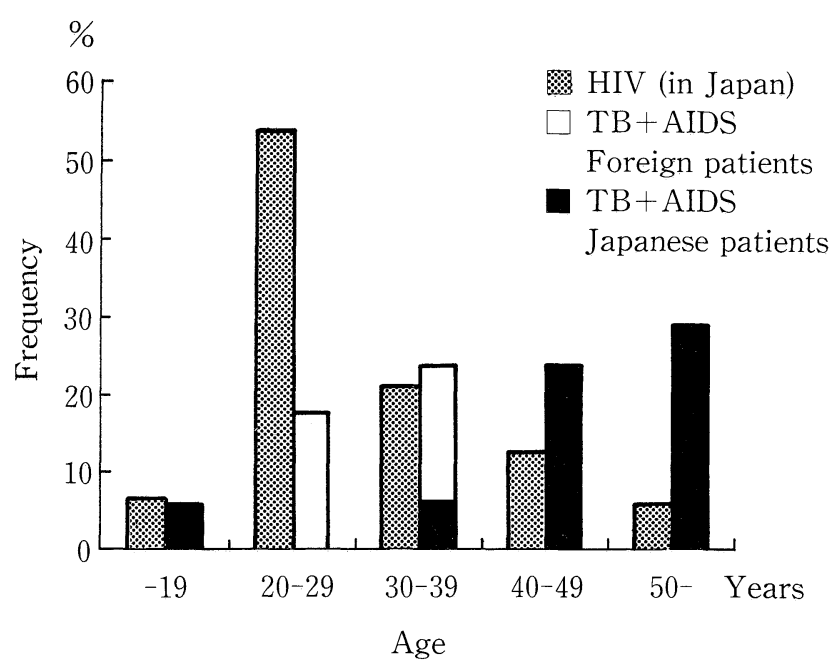

Figure 1. The age distributions of HIV-positive patients in Japan and those with pulmonary tuberculosis with AIDS (TB+AIDS) in this study. The Japanese patients (black column) were mainly distributed in the age groups above 40 years old. lymphadenitis, two miliary tuberculosis, one meningitis and one urinary tract tuberculosis. Peripheral white blood cell counts were normal. Peripheral lymphocyte counts were, however, decreased (overall mean: $19.5 \%, 1,002 / \mathrm{mm}^{3}$ ), with markedly decreased CD4 cell counts and CD4/CD8 (Table 2). Ten Japanese patients $(91 \%)$ had CD4 cell counts below $200 / \mathrm{mm}^{3}$ and their median CD4 cell count was $13 / \mathrm{mm}^{3}$. There was a significant difference in the numbers of peripheral CD4 cell counts between Japanese and foreign patients $(\mathrm{p}<0.05)$. Thus far, seven of the Japanese patients $(64 \%)$ have died. The most common symptoms were fever $(89 \%)$ and cough $(47 \%)$, which were followed by sputum production, weight loss, dyspnea and general malaise (Table 3). The Japanese patients had more typical complications of AIDS such as pneumocystis carinii pneumonia, cytomegalovirus infection and Kaposi's sarcoma (Table 4).

Five Japanese patients (45\%) showed an upper and middle lung field predilection in the vertical distribution of parenchymal infiltrates on chest X-rays (Table 5). The other five Japanese patients showed a generalized distribution of infiltrates. The chest X-ray and CT scan findings of these patients suggested 
bronchial spread of the disease (Fig. 2). Five foreign patients $(83 \%)$ showed upper and middle lung zone predominance and one had a miliary distribution. When the subjects were classified by CD4 cell counts, generalized X-ray infiltrates consti-

Table 3. Symptoms Observed in Patients with Pulmonary Tuberculosis Associated with AIDS

\begin{tabular}{lcccc}
\hline & $\begin{array}{c}\text { Japanese } \\
(\mathrm{n}=11)\end{array}$ & $\begin{array}{c}\text { Foreign } \\
(\mathrm{n}=6)\end{array}$ & \multicolumn{2}{c}{ Overall } \\
& & $(\mathrm{n}=17)$ & Percent (\%) \\
\hline Fever & 9 & 6 & 15 & $89 \%$ \\
Cough & 5 & 3 & 8 & $47 \%$ \\
Sputum & 2 & 3 & 5 & $29 \%$ \\
Body weight loss & 3 & 1 & 4 & $24 \%$ \\
Dyspnea & 3 & 1 & 4 & $24 \%$ \\
General malaise & 3 & 1 & 4 & $24 \%$ \\
Diarrhea & 1 & 2 & 3 & $18 \%$ \\
Loss of appetite & 1 & 1 & 2 & $12 \%$ \\
Others & 4 & 2 & 6 & $35 \%$ \\
\hline
\end{tabular}

Table 4. Major Complications Observed in Patients with Pulmonary Tuberculosis Associated with AIDS

\begin{tabular}{lcc}
\hline & $\begin{array}{c}\text { Japanese } \\
(\mathrm{n}=11)\end{array}$ & $\begin{array}{c}\text { Foreign } \\
(\mathrm{n}=6)\end{array}$ \\
\hline P. carinii pneumonia & 5 & 1 \\
Cytomegalovirus infection & 4 & 0 \\
Kaposi's sarcoma & 3 & 0 \\
Herpes virus infection & 2 & 1 \\
Encephalopathy & 1 & 1 \\
Malignant lymphoma & 1 & 0 \\
Fulminant cryptococcosis & 1 & 0 \\
Pancytopenia & 1 & 0 \\
Adrenal insufficiency & 1 & 0 \\
Disseminated intravascular coagulation & 0 & 1 \\
\hline
\end{tabular}

tuted a characteristic pattern in those with CD4 cell counts below $200 / \mathrm{mm}^{3}$. Four Japanese (36\%) and two foreign patients (33\%) had cavities, which were located in the upper lung field in five of these six patients. One patient had thin-walled cavities, and the autopsy of this patient revealed poor granuloma formation with a milder degree of caseation necrosis and fibrosis than the cavitation typically seen in HIV negative patients (10). No pleural effusions were observed in this series of patients. Hilar and mediastinal lymphadenopathies were common, affecting 53\% and 59\%, respectively (Table 5).

Isoniazid (INH) and rifampicin (RFP) were used in all patients. Ethambutol (EB) was added in 15 patients, streptomycin (SM) in seven, and pyrazinamide (PZA) in three. Eight patients were initially treated with triple-drug regimens; nine patients with four-drug regimens. Five Japanese and four foreign patients $(41 \%)$ suffered adverse reactions to the antituberculosis drugs. These were fever and skin rash induced by RFP in three patients; liver dysfunction in two; granulocytopenia, thrombocytopenia, loss of appetite and vertigo in one patient each. The drug susceptibilities of $M$. tuberculosis isolates are shown in Table 6. Three out of 15 isolates $(20 \%)$ demonstrated SM-resistance. One patient had a strain which was incompletely resistant to EB. All isolates were susceptible to INH and RFP at the time of diagnosis. The strain cultured a few months after the initiation of anti-tuberculosis chemotherapy in case 8 ( 8 b, Table 6$)$ was, however, multidrugresistant, showing complete resistance to RFP and SM, and incomplete resistance to $\mathrm{TH}, \mathrm{INH}(0.1 \mathrm{mcg} / \mathrm{ml})$ and $\mathrm{EB}(2.5$ $\mathrm{mcg} / \mathrm{ml}$ ). The reason for the change in drug-resistance pattern was not ascertained clinically.

\section{Discussion}

We have studied 11 Japanese and six foreign patients with pulmonary tuberculosis associated with AIDS in the 48 institutes surveyed around the Tokyo metropolitan area. The average number of patients per institute was only 0.37 , which was considerably lower than we expected. Those with associated

Table 5. Chest X-ray Findings of Patients with Pulmonary Tuberculosis Associated with AIDS, Subclassified by Ethnic Groups and CD4 Cell Counts

\begin{tabular}{|c|c|c|c|c|c|c|}
\hline & \multicolumn{2}{|c|}{ Ethnicity } & \multicolumn{2}{|c|}{ CD4 cells } & \multicolumn{2}{|c|}{ Overall } \\
\hline & $\begin{array}{c}\text { Japanese } \\
(\mathrm{n}=11)\end{array}$ & $\begin{array}{c}\text { Non-Japanese } \\
\quad(n=6)\end{array}$ & $\begin{array}{c}<200 / \mathrm{mm}^{3} \\
(\mathrm{n}=13)\end{array}$ & $\begin{array}{c}>=200 / \mathrm{mm}^{3} \\
(n=4)\end{array}$ & $(n=17)$ & Percent (\%) \\
\hline \multicolumn{7}{|l|}{ Parenchymal abnormalities; } \\
\hline Upper/middle predilection & 5 & 5 & 6 & 4 & 10 & $59 \%$ \\
\hline Generalized infiltration & 5 & 1 & 6 & 0 & 6 & $35 \%$ \\
\hline None & 1 & 0 & 1 & 0 & 1 & $6 \%$ \\
\hline Cavitation & 4 & 2 & 3 & 3 & 6 & $35 \%$ \\
\hline Pleural effusion & 0 & 0 & 0 & 0 & 0 & $0 \%$ \\
\hline \multicolumn{7}{|l|}{ Lymphadenopathy; } \\
\hline Hilar & 7 & 2 & 8 & 1 & 9 & $53 \%$ \\
\hline Mediastinal & 7 & 3 & 9 & 1 & 10 & $59 \%$ \\
\hline
\end{tabular}




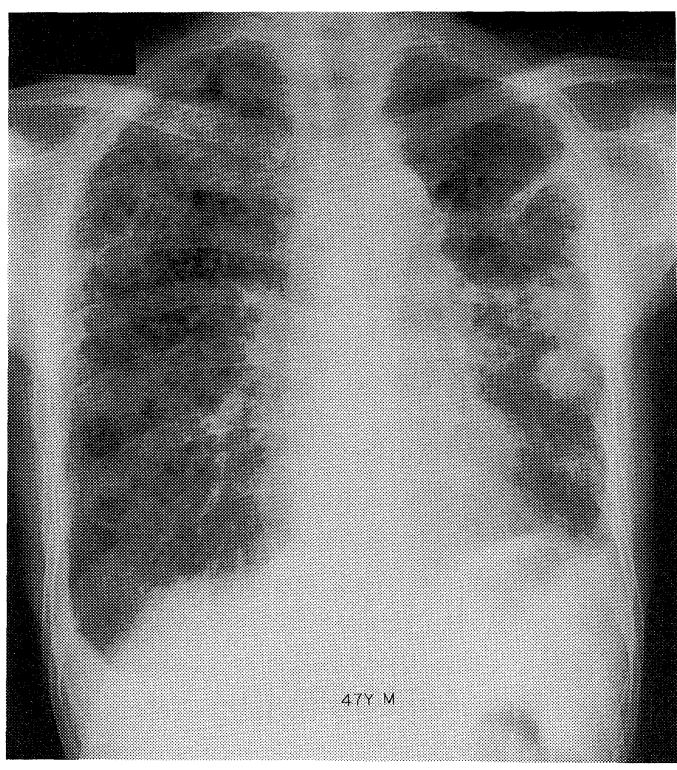

A

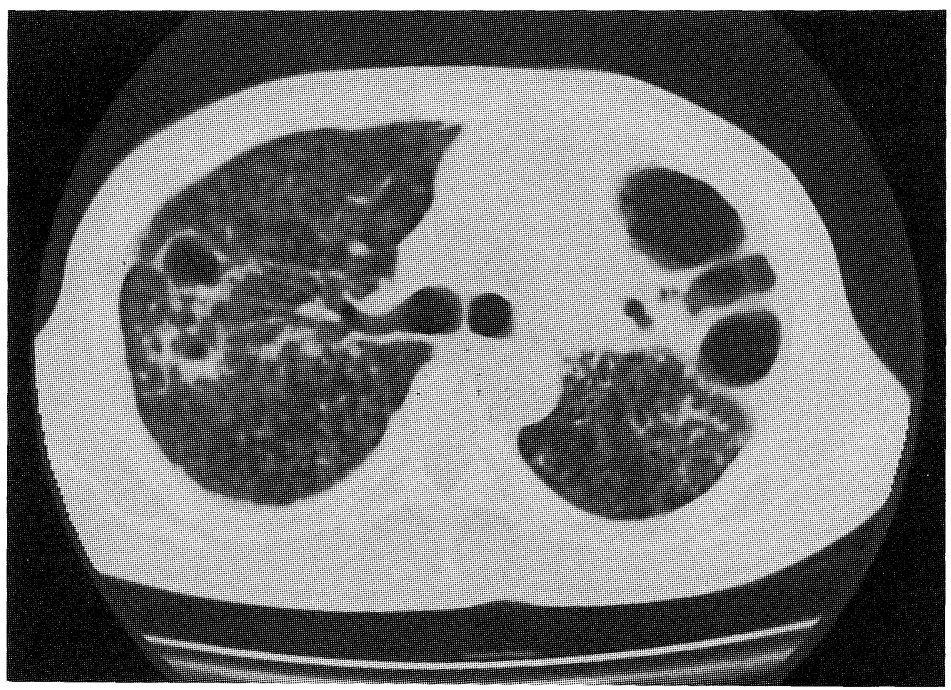

B

Figure 2. The chest X-ray (A) and CT scan (B) of case 3, a 49-year-old Japanese male patient with pulmonary tuberculosis with AIDS. The patient had diffusely distributed infiltrates with multiple cavities in the right upper field and a giant bulla in the left apex. This patient had hilar and mediastinal adenopathy (not shown in the figures).

Table 6. Drug Susceptibility of Mycobacterium tuberculosis Isolates from Each Subject

\begin{tabular}{|c|c|c|c|c|c|c|c|c|c|c|}
\hline $\begin{array}{l}\text { Concentrat } \\
(\mathrm{mcg} / \mathrm{ml})\end{array}$ & $\begin{array}{l}\text { SM } \\
\text { tion } \\
20\end{array}$ & INH & RFP & $\mathrm{EB}$ & PAS & $\mathrm{KM}$ & $\mathrm{TH}$ & $\mathrm{CPM}$ & $\mathrm{CS}$ & EVM \\
\hline \multicolumn{11}{|l|}{ Japanese; } \\
\hline case 1 & - & - & - & - & + & - & - & - & - & - \\
\hline case 3 & - & - & - & + & - & + & - & ++ & - & + \\
\hline case 4 & - & - & - & - & - & + & - & + & - & - \\
\hline case 5 & - & - & - & - & - & - & - & - & - & - \\
\hline case 6 & - & - & - & - & - & - & - & - & - & - \\
\hline case 7 & - & - & - & - & - & ND & ND & ND & ND & ND \\
\hline case $8 a$ & - & - & - & - & - & - & - & ND & ND & ND \\
\hline $8 b^{*}$ & ++ & $(+)^{* *}$ & ++ & $(+)^{* *}$ & - & - & + & ND & ND & ND \\
\hline case 9 & - & - & - & - & - & - & - & ND & ND & ND \\
\hline case 10 & ++ & $(+)^{* *}$ & - & - & - & - & - & - & - & - \\
\hline
\end{tabular}

$\begin{array}{rccccccccccc}\text { Foreign; } & & & & & & & & & & & \\ \text { case A } & - & - & - & - & + & - & - & - & - & - \\ \text { case B } & ++ & - & - & - & - & - & - & \text { ND } & \text { ND } & \text { ND } \\ \text { case C } & - & - & - & - & - & - & - & - & - & - \\ \text { case D } & - & - & - & - & - & - & - & - & - & - \\ \text { case F } & - & - & - & - & - & - & - & \text { ND } & \text { ND } & \text { ND }\end{array}$

SM: streptomycin, INH: isoniazid, RFP: rifampicin, EB: ethambutol, PAS: para-aminosalicylic acid, KM: kanamycin, TH: ethionamide, CPM: capreomycin, CS: cycloserine, EVM: emviomycin, ND: not done, ++ complete resistance, + incomplete resistance, - susceptible. *strain cultured a few months after the initiation of tuberculosis chemotherapy. ${ }^{* *}$ incomplete resistance to concentrations lower than those indicated, $0.1 \mathrm{mcg} / \mathrm{ml}$ for INH and $2.5 \mathrm{mcg} / \mathrm{ml}$ for EB. pulmonary tuberculosis, however, consisted of $29 \%$ of the AIDS patients admitted to the pulmonary divisions of these institutes. This figure suggests that patients presenting pulmonary signs and symptoms with AIDS should always be suspected of having tuberculosis. Tokyo Metropolitan Komagome Hospital has treated eight patients with tuberculosis among 456 HIV-positive (1.8\%) and 126 AIDS patients (6.8\%). There were two patients with atypical mycobacteriosis in this survey, accounting for $10 \%$ of AIDS patients in whom acid-fast bacilli were infected.

Basic features observed in the Japanese patients were; 1) middle aged male, 2) advanced HIV infection, and 3) poor prognosis. The age distribution of these patients $(83 \%$ were more than 40 years old) appears to reflect the age distribution of tuberculosis rather than that of HIV, and the age distribution seems unrelated to AIDS progression. Seventy-one percent of newly registered patients with tuberculosis in Tokyo were more than 40 years of age (24), while only $18.3 \%$ of HIV-positive patients in Japan were more than 40 years old (25). The foreign patients, however, were in their twenties and thirties. The age distribution suggests that tuberculosis in the Japanese patients is mostly of the reactivation form, and that tuberculosis is well controlled among the young. The CD4 cell counts were below $200 / \mathrm{mm}^{3}$ in ten Japanese patients. The median CD4 cell count in Japanese patients was $13 / \mathrm{mm}^{3}$. Eight patients had AIDSindicator diseases other than tuberculosis (case 4-11, Table 4). Five Japanese patients showed generalized infiltrates on chest X-rays. All of these findings support the assumption that these patients were in the advanced stage of HIV infection, as characterized by decreased CD4 cell counts $(5,11,26)$. The prognosis of these patients was, accordingly, poor. 
A middle aged man, presenting fever and cough, nonspecific chest X-ray infiltrates, normal white blood cell counts, and a negative tuberculin skin test may be the general clinical presentation of Japanese patients. This somewhat atypical clinical picture may delay the diagnosis, unless a sputum smear is examined (27). Elliot et al, working in Zambia (28), reported that tuberculosis patients with HIV-positivity showed a trend towards a lower grade or even negative sputum smear and lower colony counts on culture. This was not, however, the case in our series in which we had a high smear-positive rate (94\%), suggesting that sputum smear may be the key to an accurate diagnosis. The high rate also suggests high communicability. Cavitation was seen in 35\% of the patients but no pleural effusion was observed. These $\mathrm{X}$-ray findings also differed from the reported findings in late HIV infection $(3-5,7,8,12)$. Nonetheless, the generalized X-ray infiltrates and lymphadenopathy were typical of advanced HIV infection $(11,26)$. We suspect that the chest $X$-ray shadows seen in Japanese patients may in part be attributable to certain characteristic features of Japanese patients, such as reactivation tuberculosis in aged subjects, though the primary etiology would be decreased CD4 cell counts (Table 5).

Extrapulmonary involvement is another important clinical aspect of HIV positive tuberculosis (6). This occurs in more than $70 \%$ of patients with tuberculosis and preexisting AIDS or AIDS diagnosed soon after the diagnosis of tuberculosis (29), but in only 24 to $45 \%$ of patients with tuberculosis alone and less advanced HIV infection $(30,31)$. The Japanese patients had, for the most part, advanced HIV infections, and five (45\%, cases $1,7,8,9,11$ ) showed extrapulmonary involvement.

At present, based on the results of this survey, resistance to anti-tuberculosis drugs seems not to be a major problem. Complete resistance to SM was seen in three patients, two Japanese and one foreign. One Japanese patient had a strain which showed incomplete resistance to EB. No isolate was multidrug-resistant at least at the time of diagnosis. These results suggest that tuberculosis with AIDS can be treated initially with INH, RFP and EB, with or without PZA. The use of SM should be withheld, unless other drugs cannot be used because of resistance and/or adverse reactions. Frequent adverse reactions to tuberculosis chemotherapy have been reported $(3,6,32)$. We found adverse reactions in $41 \%$ of the patients in this series.

Multidrug-resistant tuberculosis in patients with HIV infection has been reported (15-18). We identified one such strain (case $8 b$ ) in this study. The frequencies of initial drug resistance to one of the major antituberculosis drugs (SM, INH, PAS) have been estimated to be about $15 \%$ for new and $40 \%$ for previously treated cases $(33,34)$. Resistance to RFP remains at approximately $1 \%$ in Japan. However, a recent report from the U.S. noted an initial drug resistance rate of 33\% in New York City. Of the 239 patients who received anti-tuberculosis therapy, $30 \%$ had isolates resistant to INH and RFP, suggesting a significant increase in multidrug-resistant tuberculosis (18). In the present study, we did identify one patient with multidrugresistant tuberculosis. Clearly, we must be vigilant in monitor- ing for the emergence of the resistant strains in this country.

In conclusion, the number of patients with pulmonary tuberculosis associated with AIDS is still limited in Japan. Tuberculosis does, however, appear to be common (29\%) among AIDS patients with pulmonary signs and symptoms. The clinical picture of a Japanese patient, based on observations made in the present study, remains speculative though the typical patient would appear to be a middle aged man with advanced HIV infection. The diagnosis may be difficult due to the atypical presentation. Sputum smear and culture are the keys to an accurate diagnosis.

Acknowledgements: The authors would like to thank the representatives of the institutes who responded to the questionnaire, and to Dr. Hideki Yotsumoto of Tokyo University for his generous advice and support in preparing the manuscript. We also thank Dr. Tadashi Fujino of the National Sanatorium Minami-Yokohama Hospital for providing the data from two of the cases presented in this study.

\section{References}

1) Sudre P, ten Dam G, Kochi A. Tuberculosis: a global overview of the situation today. Bull World Health Organ 70: 149, 1992.

2) Center for Disease Control: 1993 Revised classification system for HIV infection and expanded surveillance case definition for AIDS among adolescents and adults. MMWR 41: 1, 1992.

3) Raviglione MC, Narain JP, Kochi A. HIV-associated tuberculosis in developing countries: clinical features, diagnosis, and treatment. Bull World Health Organ 70: 515, 1992.

4) Pitchenik AE, Rubinson HA. The radiographic appearance of tuberculosis in patients with the acquired immune deficiency syndrome (AIDS) and pre-AIDS. Am Rev Respir Dis 131: 393, 1985.

5) Goodman PC. Pulmonary tuberculosis in patients with acquired immunodeficiency syndrome. J Thorac Imag 5: 38, 1990.

6) Barnes PF, Bloch AB, Davidson PT, Snider DE Jr. Tuberculosis in patients with human immunodeficiency virus infection. N Engl J Med 324: 1644, 1991.

7) Long R, Maycher B, Scalcini M, Manfreda J. The chest roentgenogram in pulmonary tuberculosis patients seropositive for human immunodeficiency virus type 1. Chest 99: 123, 1991.

8) Hill AR, Premkumar S, Brustein S, et al. Disseminated tuberculosis in the acquired immunodeficiency syndrome era. Am Rev Respir Dis 144: 1164, 1991.

9) De Cock KM, Soro B, Coulibaly IM, Lucas SB. Tuberculosis and HIV infection in Sub-Saharan Africa. JAMA 268: 1581, 1992.

10) Batungwanayo J, Taelman H, Dhote R, Bogaerts J, Allen S, Van de Perre P. Pulmonary tuberculosis in Kigali, Rwanda. Impact of human immunodeficiency virus infection on clinical and radiographic presentation. Am Rev Respir Dis 146: 53, 1992.

11) Jones BE, Young SMM, Antoniskis D, Davidson PT, Kramer F, Barnes PF. Relationship of the manifestations of tuberculosis to CD4 cell counts in patients with human immunodeficiency virus infection. Am Rev Respir Dis 148: 1292, 1993.

12) Mlika-Cabanne N, Brauner M, Mugusi F, et al. Radiographic abnormalities in tuberculosis and risk of coexisting human immunodeficiency virus infection. Results from Dar-es-Salaam, Tanzania, and scoring system. Am J Respir Crit Care Med 152: 786, 1995.

13) Mlika-Cabanne N, Brauner M, Kamanfu G, et al. Radiographic abnormalities in tuberculosis and risk of coexisting human immunodeficiency virus infection. Methods and preliminary results from Bujumbura, Burundi. Am J Respir Crit Care Med 152: 794, 1995.

14) Narain JP, Raviglione MC, Kochi A. HIV-associated tuberculosis in developing countries: epidemiology and strategies for prevention. Tuber Lung Dis 73: 311, 1992. 


\section{KANAZAWA et al}

15) Center for Disease Control. Nosocomial transmission of multidrugresistant tuberculosis among HIV-infected persons - Florida and New York, 1988-1991. MMWR 40: 585, 1991.

16) Fischl MA, Uttamchandani RB, Daikos GL, et al. An outbreak of tuberculosis caused by multiple-drug-resistant tubercle bacilli among patients with HIV infection. Ann Intern Med 117: 177, 1992.

17) Edlin BR, Tokars JI, Grieco MH, et al. An outbreak of multidrug-resistant tuberculosis among hospitalized patients with the acquired immunodeficiency syndrome. N Engl J Med 326: 1514, 1992.

18) Frieden TR, Sterling T, Pablos-Mendez A, Kliburn JO, Caauthen GM, Dooley SW. The emergence of drug-resistant tuberculosis in New York City. N Engl J Med 328: 521, 1993.

19) Shishido H, Hebisawa A, Nagai H, et al. An autopsied case with AIDS diagnosed at the onset of pulmonary tuberculosis. Nippon Iji Shinpo 3612: 37, 1993 (in Japanese).

20) Hirokawa M, Suzuki Y, Kodama H, et al. A case of AIDS with the leading symptom of alopecia followed by disseminated tuberculosis. Kokyu 13: 196, 1994 (Abstract in English).

21) Arai $Y$, Sato R, Katsura T, et al. A case report of the atypical tuberculosis associated with AIDS. Kekkaku 70: 431, 1995 (Abstract in English).

22) Naganuma $M$, Toyoda $T$, Osumi $M$, et al. A case of AIDS with bronchial tuberculosis. Kekkaku 71: 345, 1996 (Abstract in English).

23) Mikami R, Haga T, Kudo S, Yotsumoto H, ed. Changes in Respiratory Clinics. A 25-year record of the Respiratory Clinical Conference. Tokyo Tanabe Quarterly 1992 Suppl (in Japanese).

24) Division of Medical Welfare, Bureau of Public Health, Tokyo Metropolitan Government: Tuberculosis in Tokyo 1993 (in Japanese).

25) Soda K, Ichikawa S, Fukutomi K, et al. Current status of HIV/AIDS epidemic in Japan. in: Yamazaki S: Health Science Research Grant; Research projects on epidemiology and control of HIV. 1994 Annual Report p20 (Abstract in English).
26) Post FA, Wood R, Pillay GP. Pulmonary tuberculosis in HIV infection: radiographic appearance is related to $\mathrm{CD} 4^{+} \mathrm{T}$-lymphocyte count. Tuber Lung Dis 76: 518, 1995.

27) Kramer F, Modilevsky T, Waliany AR, Leedom JM, Barnes PF. Delayed diagnosis of tuberculosis in patients with human immunodeficiency virus infection. Am J Med 89: 451, 1990.

28) Elliott AM, Namaambo K, Allen BW, et al. Negative sputum smear results in HIV-positive patients with pulmonary tuberculosis in Lusaka, Zambia. Tuber Lung Dis 74: 191, 1993.

29) Sunderam G, McDonald RJ, Maniatis T, Oleske J, Kapila R, Reichman LB. Tuberculosis as a manifestation of the acquired immunodeficiency syndrome (AIDS). JAMA 256: 362, 1986.

30) Theuer CP, Hopewell PC, Elias D, Schecter GF, Rutherford GW, Chaisson RE. Human immunodeficiency virus infection in tuberculosis patients. J Infect Dis 162: 8, 1990.

31) Pitchenik AE, Burr J, Suarez M, Fertel D, Gonzales G, Moas C. Human T-cell lymphotropic virus-III (HTLV-III) seropositive and related disease among 71 consecutive patients in whom tuberculosis was diagnosed: a prospective study. Am Rev Respir Dis 135: 875, 1987.

32) Small PM, Schecter GF, Goodman PC, Sande MA, Chaisson RE, Hopewell PC. Treatment of tuberculosis in patients with advanced human immunodeficiency virus infection. N Engl J Med 324: 289, 1991.

33) Tuberculosis Research Committee, Ryoken. A study on prevalence of resistance to major drugs among newly admitted pulmonary tuberculosis patients in 1972. Part 1. Comparison of result in 1972, with those in 1957, '59, '61, '63, '66 and '69. Kekkaku 50: 1, 1975 (Abstract in English).

34) Tuberculosis Research Committee, Ryoken. A study on prevalence of resistance to major drugs among newly admitted pulmonary tuberculosis patients in 1972. Part 2. Studies in the factors related to the prevalence of drug resistance. Kekkaku 50: 55, 1975 (Abstract in English). 